\title{
Fluctuation model for compositional heterogeneity in skarn clinopyroxenes
}

\author{
TAKANORI NAKANO \\ Institute of Geoscience, University of Tsukuba, Tennoudai 1-1-1, \\ Tsukuba-shi, Ibaraki, 305 Japan
}

(Received February 20, 1989; Accepted October 21, 1989)

\begin{abstract}
A model incorporating experimentally determined fluid-crystal cation exchange equilibrium constants is proposed to explain compositional variations in clinopyroxene from Japanese skarns. The proposed "Fluctuation Model" can account for the observed compositional heterogeneity in both individual and aggregate clinopyroxene grains on a thin section scale. The model assumes formation from a hydrothermal solution whose mean concentrations of magnesium, manganese and iron components remained essentially constant throughout crystal growth period at constant temperature and pressure. Compositional heterogeneity developed as a result of local spatial and temporal fluctuations about the mean solution component concentrations.

The degree of fluctuation in the proportion of component $i$ in the hydrothermal solution, as defined by the percent coefficient of variation, $C V_{i}$, is linearly related to the mean mole percent, $M_{i}$, of the component in the hydrothermal solution by the equation $C V_{i}=0.25 \times\left(100-M_{i}\right)$. Various compositional patterns of naturally occurring skarn clinopyroxenes can be closely reproduced by the model.
\end{abstract}

\section{INTRODUCTION}

Calcium-rich clinopyroxene is one of the most commonly occurring minerals in skarn deposits. Numerous electron probe micro analysis (EPMA) studies have revealed that the mineral chemistry of clinopyroxene in skarn deposits can be highly variable depending upon such factors as the ore-metal, host rock and mineral assemblage in which the clinopyroxene occurs (e.g. Einaudi and Burt, 1982; Einaudi, 1977). Compositional variations within an individual grain may even occur, although zonation patterns within single grains are not always systematic (Burton et al., 1982; Nakano, 1982; Meinert, 1987).

The compositional pattern both within individual clinopyroxene grains and among individual grains within a granular aggregate may provide constraints on the mechanism controlling clinopyroxene composition and on the evolution of the skarn-forming fluid. However, few theories exist to explain development of clinopyroxene compositional variations, partly owing to a lack of compositional mappings of single grains. In this article, heterogeneous compositional patterns for an aggregate of clinopyroxene grains are preliminarily reported and discussed on the basis of experimental data on cation exchange equilibria between hydrothermal fluid and clinopyroxene.

Samples analyzed in this study were collected from seven Japanese metalliferous skarn deposits. Most of these were clinopyroxene skarn with small amounts of secondary amphibole replacing clinopyroxene and trace amounts of interstitial calcite and/or quartz. Most chemical analyses were made on polished sections using randomly selected grains. Detailed chemical analyses were also performed on randomly selected grains on polished sections to document internal compositional variations. The samples' equigranular texture made paragenesis determination or the growth se- 

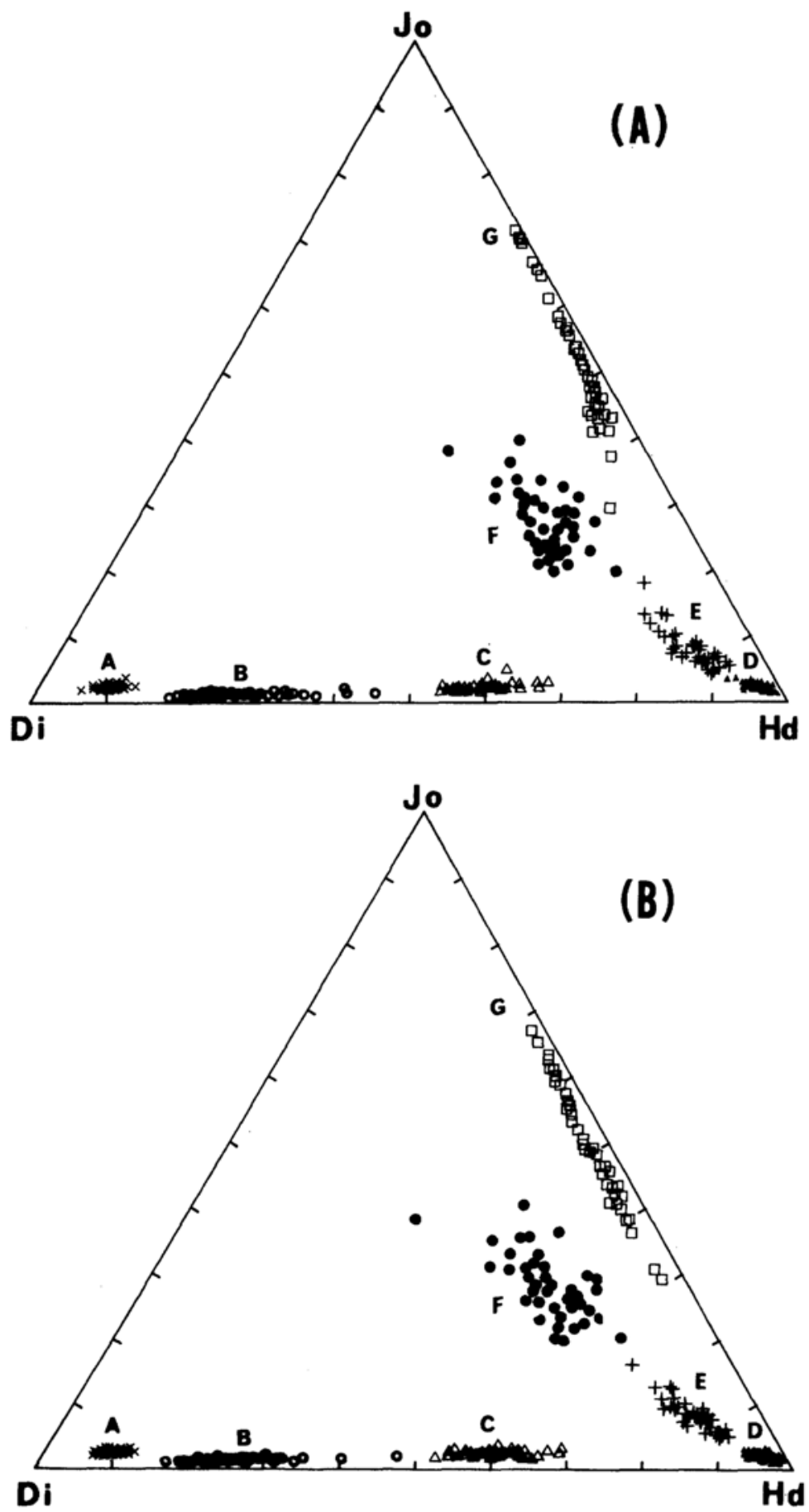

Fig. 1. (A) Chemical compositions of clinopyroxenes from clinopyroxene skarns $(A-G)$ in seven Japanese skarn deposits: A-Horado(Pb, Zn), B-Oomine(Cu), C-Kobushi(Fe), D-Higashikibe(Fe), E-Kagata(W), FFumuro $(\mathrm{Pb}, \mathrm{Zn})$ and $\mathrm{G}$-Chichibu $(\mathrm{Fe}, \mathrm{Cu}, \mathrm{Pb}, \mathrm{Zn})$ mine. Analyses are expressed in mole percent proportions of diopside (Di), johannsenite (Jo) and hedenbergite (Hd) components. An average of 40 individual clinopyroxene grains were analyzed from each skarn. (B) The calculated simulation of clinopyroxene composition for individual grains illustrated in (A). Note the similar pattern of compositions of clinopyroxenes in both Figures. For further details, see Text. 

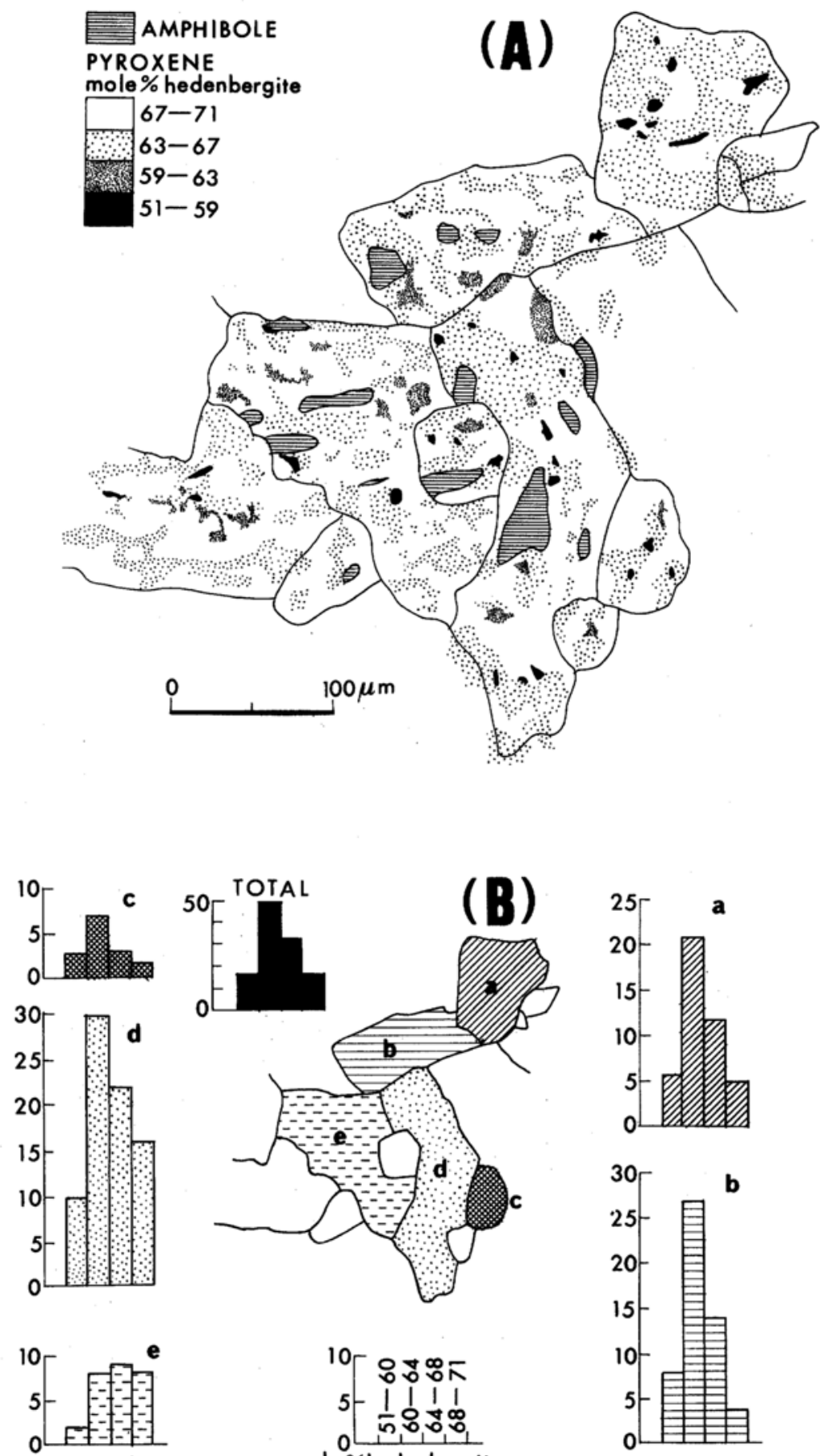

Fig. 2. (A) Compositional map of an aggregate of clinopyroxene grains in a clinopyroxene skarn from the Shinyama deposit in the Kamaishi mine, northeastern Japan. This map was prepared from analyses performed on an approximately $10 \times 10 \mu \mathrm{m}$ grid overlain on the granular aggregate. Note the existence of some ambiguous patterns resembling ink-blots. (B) Compositional histogram for individual clinopyroxene grains shown in (A) and an aggregate histogram for all analyses. The compositional interval in the histogram is slightly different from $(A)$ to illustrate that no distinct compositional characteristics are observed for any of the grains a to $e$. 
quence of individual grains almost impossible.

A JEOL-50A EPMA at the Chemical Analysis Center, University of Tsukuba, was used for the chemical analyses of $\mathrm{Si}, \mathrm{Al}, \mathrm{Ti}, \mathrm{Mg}$, $\mathrm{Mn}, \mathrm{Fe}, \mathrm{Ca}, \mathrm{Na}$ and $\mathrm{K}$. The $\mathrm{Na}_{2} \mathrm{O}, \mathrm{Al}_{2} \mathrm{O}_{3}, \mathrm{TiO}_{2}$ and $\mathrm{K}_{2} \mathrm{O}$ contents of the clinopyroxenes all fell below 0.5 weight percent. Therefore, the mineral chemistry of skarn clinopyroxene is best expressed by a mole ratio of the ternary diopside $\left(\mathrm{CaMgSi}_{2} \mathrm{O}_{6}\right)$, johannsenite $\left(\mathrm{CaMnSi}_{2} \mathrm{O}_{6}\right)$ and hedenbergite $\left(\mathrm{CaFeSi}_{2} \mathrm{O}_{6}\right) \quad$ components. Analytical errors in the ternary system were within 1 mole percent for each clinopyroxene component.

\section{Analytical Results}

Representative chemical compositions of clinopyroxenes analyzed in this study are given on the ternary diopside-johannsenitehedenbergite diagram in Fig. 1(A). This figure illustrates the large variety of compositions and intragranular compositional variations in the clinopyroxenes. Furthermore single grains within individual samples also display similar compositional ranges.

Nakano (1982) reported heterogeneous compositional patterns for some clinopyroxenes in the clinopyroxene skarn from the Shinyama deposit in the Kamaishi mine, northeastern Japan. One example is illustrated in Fig. 2. In this case, the clinopyroxenes contain 27-48 mole percent diopside, 1-2 mole percent johannsenite and 51-71 mole percent hedenbergite. Some mottled compositional patterns exist in the aggregate of clinopyroxene grains (Fig. 2(A)), however, all grains show the similar compositional character (Fig. 2(B)).

Preliminary study for the compositional mapping of the above seven clinopyroxenes in Fig. 1(A) seems to confirm this tendency; no systematic compositional patterns were detected in either individual grains or granular aggregates. Moreover, no compositional halos were observed in the clinopyroxenes along the contact with secondary minerals. This suggests that the observed compositional heterogeneity in clinopyroxene was not produced by alteration with later fluids of different compositions. The detailed compositonal maps will be reported elsewhere.

Since the contrasting textural homogeneity (eqigranular) and compositional heterogeneity (mottled) exists in all of the clinopyroxene aggregates, the magnesium, manganese and iron proportions in the hydrothermal fluid may be non-uniform even on the scale of a polished thin section. The similar compositional ranges and patterns observed on both granular aggregate and individual grain scales suggest that the mean $\mathrm{Mg}, \mathrm{Mn}$ and $\mathrm{Fe}$ proportions in the hydrothermal fluid did not change systematically during the crystal growth, but rather fluctuated similarly with time and space around their mean values at constant temperatures and pressures. In other words, the clinopyroxene skarn was formed in a system where the average proportions of the three components in the hydrothermal fluid remained constant both temporally and spatially on a thin section scale.

\section{FluCtuation MOdel}

One possible explanation for the above compositional variety and heterogeneity in skarn clinopyroxenes, termed hereafter as the Fluctuation Model, is presented. This model assumes the following two conditions: (a) Surface equilibrium for the magnesium, manganese and iron components is attained between a growing clinopyroxene crystal and hydrothermal fluids. These relations are given by the following equations:

$$
\begin{aligned}
& (\mathrm{Mn} / \mathrm{Mg})_{\mathrm{cpx}}=K_{1} \times(\mathrm{Mn} / \mathrm{Mg})_{\text {fluid }} \\
& (\mathrm{Mn} / \mathrm{Fe})_{\mathrm{cpx}}=K_{2} \times(\mathrm{Mn} / \mathrm{Fe})_{\text {fluid }} \\
& (\mathrm{Fe} / \mathrm{Mg})_{\mathrm{cpx}}=K_{3} \times(\mathrm{Fe} / \mathrm{Mg})_{\text {fluid }}
\end{aligned}
$$

where $K_{1}, K_{2}$ and $K_{3}$ are partition coefficients and cpx and fluid denote clinopyroxene and a hydrothermal fluid, respectively. (b) The three components in the hydrothermal fluid fluctuates independently from one another. This condition assumes that the proportion of an individual 

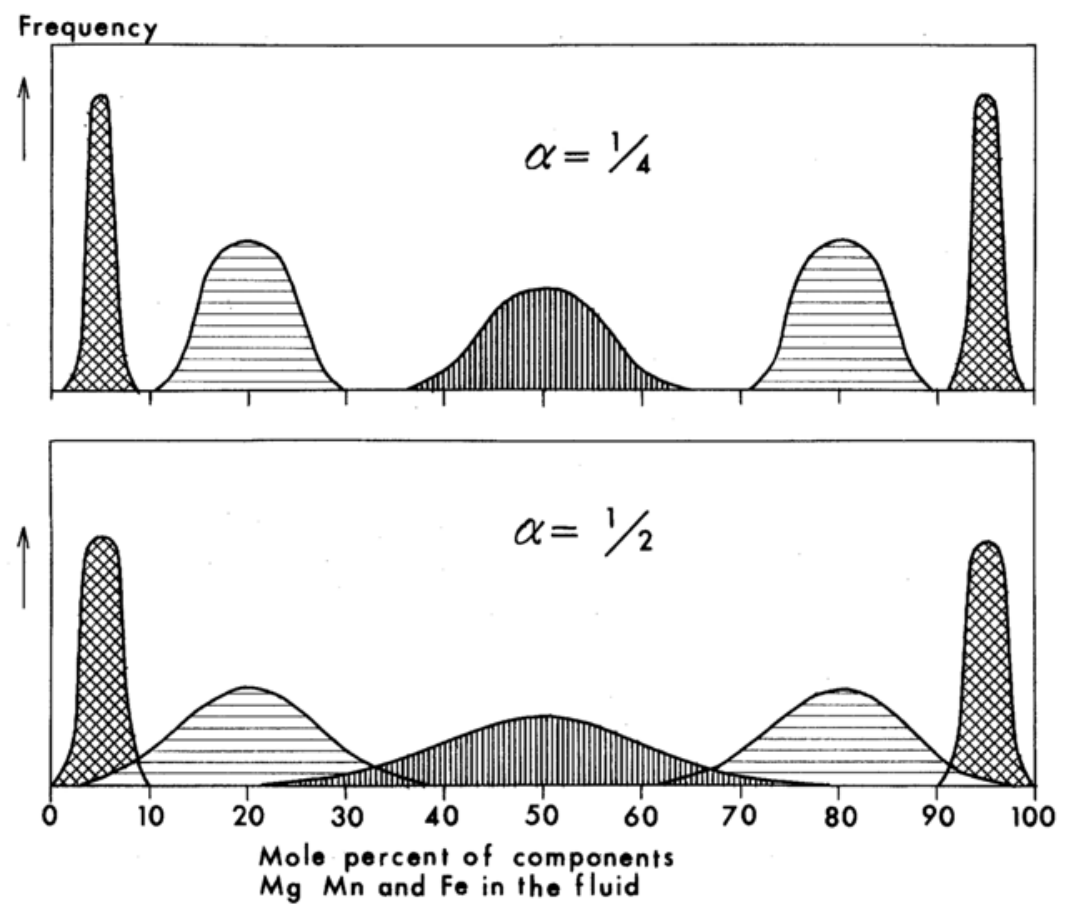

Fig. 3. Schematic representation of the Fluctuation Model. Components $\mathrm{Mg}, \mathrm{Mn}$ or Fe in the hydrothermal fluid show a normal distribution in their mole proportions in terms of mean mole percent. Two cases are shown for different $\alpha$ values of the constant in Eq. (5): $\alpha=0.25$ in the upper figure and $\alpha=0.5$ in the lower. For further details, see Text.

component in the hydrothermal fluid will show a "normal" or Gaussian distribution around its arithmetic mean proportion. As a boundary condition the standard deviation of the mole proportion of each component is defined as 0 when its mean mole proportion is either 0 or 1 . Thus, the following equation is used to relate the standard deviation of the mole proportion of component $i$ $\left(\sigma_{i}\right)$ to its mean mole proportion $\left(M_{i}\right)$ :

$$
\sigma_{i}=\alpha \times M_{i} \times\left(100-M_{i}\right) / 100
$$

where $\alpha$ is a unitless and experimentally determined constant and $\sigma_{i}$ and $M_{i}$ are expressed in mole percent. Noting that the percent coefficient of variation $\left(C V_{i}\right)$ equals $100 \sigma_{i} / M_{i}$, Eq. (4) can be rearranged into the following linear form:

$$
C V_{i}=\alpha \times\left(100-M_{i}\right) \text {. }
$$

Thus, by using the Fluctuation Model, the degree of fluctuation of each component is assumed to depend only on its mean mole ratio for given values of $\alpha$ and partition coefficients $K_{1}, K_{2}$ and $K_{3}$. In Fig. 3, five cases are schematically depicted for a component with mean mole fluid percentages of 5, 20, 50, 80 and 95 percent in which the constant $\alpha$ has values of 0.25 (above) and 0.5 (below). Notice that the standard deviation shows a symmetrical pattern with a maximum value at 50 mole percent of the mean value.

\section{Results AND Discussion}

Skarn clinopyroxene compositions of individual skarn samples were calculated according to the following procedure. Analytical data of clinopyroxene were at first recalculated into mole percentages of the components, magnesium, manganese and iron; these values were then substituted into Eqs. (1)-(3) to obtain mean molar ratios of the corresponding component in the hydrothermal fluid. 


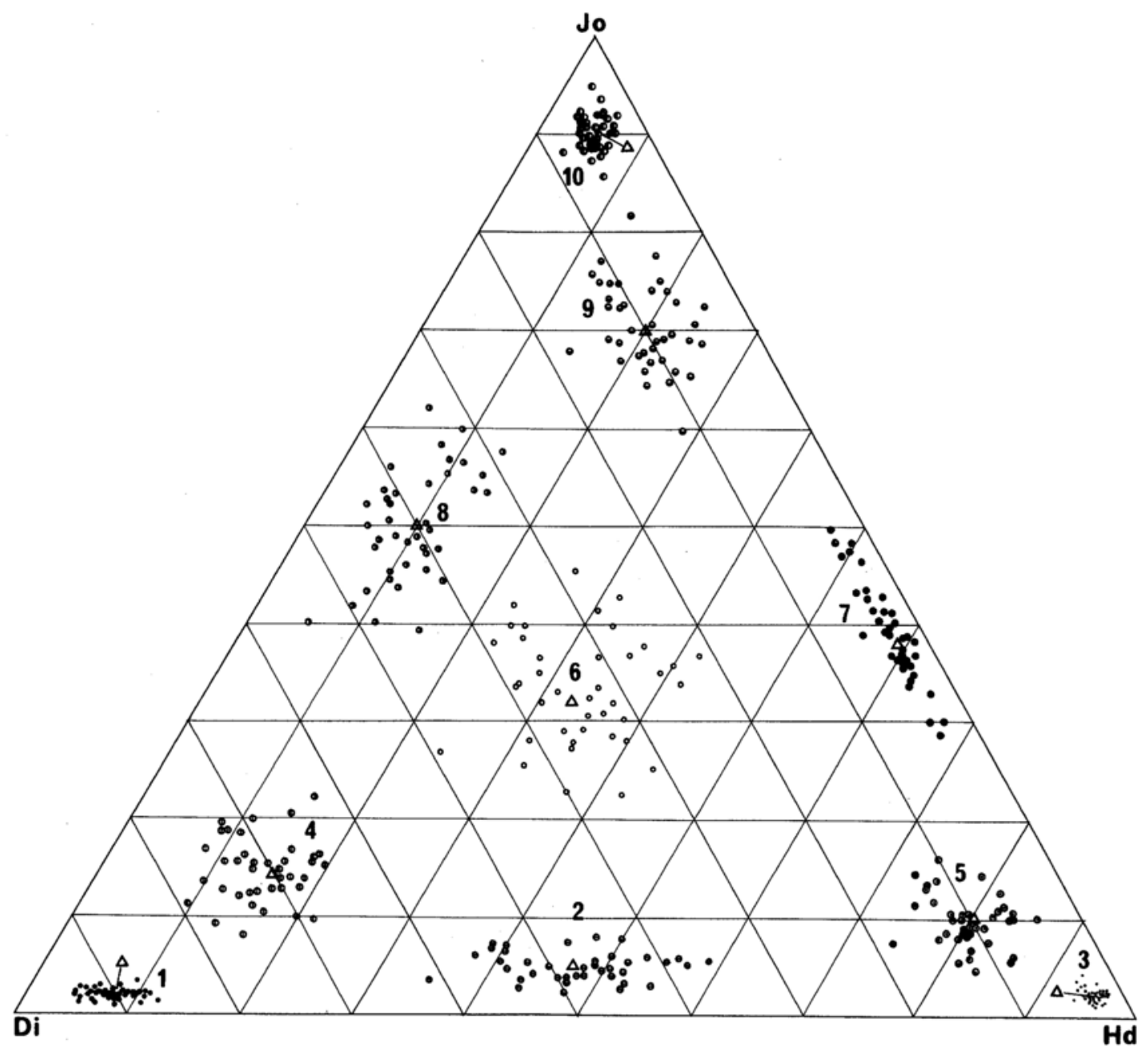

Fig. 4. Ternary plot of the compositional variation of clinopyroxenes reproduced by the Fluctuation Model. Ten cases (1-10) of different mean clinopyroxene compositions ( $\Delta$ ) are shown schematically. In this calculation the partition coefficients $K_{1}, K_{2}$ and $K_{3}$ in Eqs. (1)-(3) are set to equal 1 and $\alpha$ is 0.25 . The number of samples in the simulation is 40 for each case.

To demonstrate that the compositional pattern of clinopyroxenes depends more strongly on their mean compositions than on values of the partition coefficients, clinopyroxene compositions due to different mean hydrothermal solution compositions are depicted in Fig. 4. In this figure, ten cases are considered in which A equals 0.25 and, for simplicity, the partition coefficients all equal 1. Even these rough approximations seem to simulate the various compositional patterns of natural clinopyroxenes in Fig. 1(A).

To carry out such calculations more accurately, the values of the partition coefficients $K_{1}, K_{2}$ and $K_{3}$ must be known. liyama $(1979,1982)$ investigated the partition relations for the three binary pairs $\mathrm{Mg}-\mathrm{Mn}, \mathrm{Mn}-\mathrm{Fe}$ and $\mathrm{Fe}-\mathrm{Mg}$ at $600^{\circ} \mathrm{C}$ and $1 \mathrm{kbar}$ (Fig. 5). The values $K_{2}$ and $K_{3}$ are evaluated from this Figure. Extension of liyama's data to the ternary $\mathrm{Mg}-\mathrm{Mn}-\mathrm{Fe}$ relations for clinopyroxenes, however, requires certain approximations because of the following three reasons; the $K_{1}, K_{2}$ and $K_{3}$ values are strictly not constant in the whole compositional range of each binary pair, an ideal solid solution is not confirmed in each pair. In addition, estimation of the partition coefficient $K_{1}$ from the exchange 


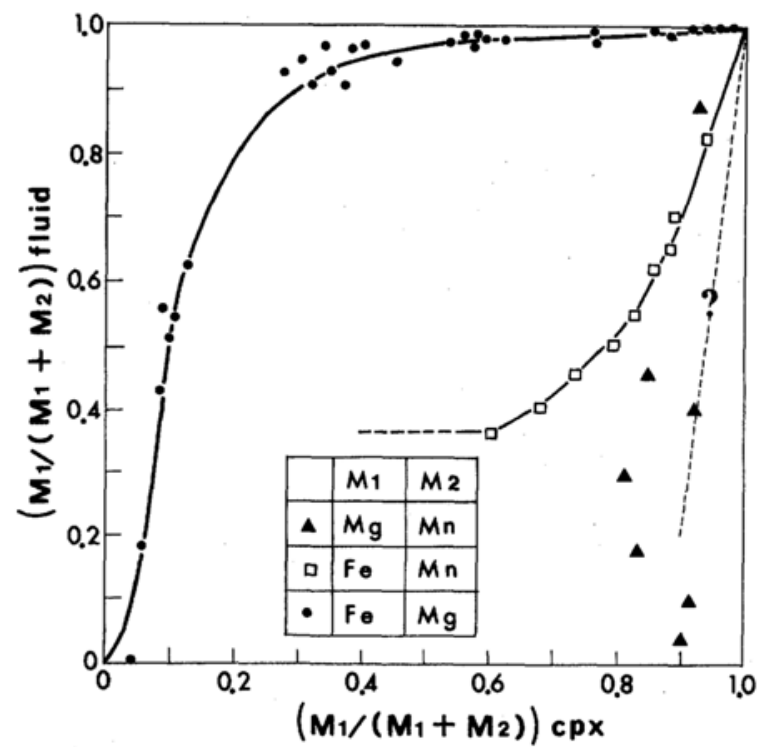

Fig. 5. Experimentally determined binary isotherms for $\mathrm{Mg}-\mathrm{Mn}, \mathrm{Fe}-\mathrm{Mn}$ and $\mathrm{Fe}-\mathrm{Mg}$ pairs in clinopyroxenes-hydrothermal fuids equilibrium at $600^{\circ} \mathrm{C}$ and 1 kbar (Iiyama 1979, 1982). The partition relation for the $M g-M n$ pair is slightly ambiguous compared to other hyperbolic isotherms.

isotherm of the Mn-Mg pair is difficult (Fig. 5).

The partition coefficients $K_{1}, K_{2}$ and $K_{3}$ are assumed to be constant between ternary clinopyroxenes and hydrothermal fluids. If this assumption is justified, $K_{1}$ can be obtained by multiplying $K_{2}$ by $K_{3}$. The distribution isotherms of the $\mathrm{Mn}-\mathrm{Fe}$ and $\mathrm{Fe}-\mathrm{Mg}$ pairs have a symmetrically hyperbolic shape, as the studied clinopyroxenes have $\mathrm{Fe} /(\mathrm{Fe}+\mathrm{Mg})$ and $\mathrm{Fe} /(\mathrm{Fe}+\mathrm{Mn})$ ratios greater than 0.1 and 0.55 , respectively (Fig. 1(A)). The assumption of constant partition coefficients appears valid for the compositional range of the analyzed clinopyroxenes. One exception is a clinopyroxene sample from the Chichibu mine (sample G in Fig. 1(A)) whose $\mathrm{Fe} /(\mathrm{Fe}+\mathrm{Mn})$ ratio, 0.3 , deviates slightly from the range of ideality in the experimental isotherm (Fig. 5).

As a whole, however, almost ideal mixing between johannsenite-hedenbergite and hedenbergite-diopside appears likely for the clinopyroxenes studied in this work. Consequently, the values of $K_{2}$ and $K_{3}$ can safely be esti- mated from Fig. 5 to fall in a narrow range between $0.03-0.05$ and $0.2-0.3$, respectively. In this case, $K_{1}$ lies between 0.006 and 0.015 . In the following calculations $K_{1}, K_{2}$ and $K_{3}$ are assumed to have constant values of $0.01,0.05$ and 0.2 , respectively.

By using computer, generated were the various fluctuations of the concentration in terms of mole percent which are the normal distribution in their shape. The generated mole percentages were subsequently transformed into mole percentages of the diopside, johannsenite and hedenbergite clinopyroxene components by Eqs. (1)-(3). These compositions were plotted on the ternary diagram and compared to the analytical data of skarn clinopyroxene. Various compositional patterns can be produced by varying the value of the standard deviation and, to a lesser degree, the combination of generated normal random numbers.

Figure 1(B) illustrates the clinopyroxene compositions reproduced by the model for the seven skarn samples shown in Fig. 1(A). In this calculation a standard deviation was assigned to each component almost equal to that of the analytical clinopyroxene compositions. Analytical data for clinopyroxenes in each skarn are presented in Table 1. The compositions of the hydrothermal fluids, which are responsible for growth of such clinopyroxenes as computed from Eqs. (1)-(3) for the mean clinopyroxene analysis of each skarn sample, are also presented in Table 1. For each skarn sample the average number of analyzed and simulated compositions was 40 .

The close resemblance of Figs. 1(A) and 1(B) suggests that the Fluctuation Model can successfully explain the compositional variation of skarn clinopyroxenes. Moreover, in the case of manganese and iron, a distinct correlation exists between the coefficients of variation in Eq. (5) and their mean proportions (Fig. 6). This relation defines a straight line which has an equation of the form:

$$
C V_{i}=0.25 \times\left(100-M_{i}\right) .
$$

Equation (6) corresponds to Eq. (5). Although the magnesium data do not show such 
a coherent relation, this is partly because the mean proportion of magnesium in the hydrothermal fluids was low and mostly ranged from less than 1 mole percent to a maximum of 17 mole percent. However, the intercept of the line representing $\alpha$ for magnesium falls in the range 13-30 mole percent which is similar to those for manganese and iron. Thus, the relation expressed in Eq. (6) seems to be valid as a first approximation for the three components.

If the calculation is performed with standard deviation values which is significantly different from those expected from Eq. (6), the similarity between Figs. 1(A) and 1(B) decreases. Therefore, the linear relation in Fig. 6 confirms the validity of the assumption such that each of the three clinopyroxene components in the hydrothermal fluid can vary independently from one another.

As shown in Fig. 1(A), the compositional variation of clinopyroxenes within a given sample increases if the mean composition of pyrox-

Table 1. Compositions of clinopyroxenes and computed coexisting fluids*

\begin{tabular}{|c|c|c|c|c|c|c|c|c|}
\hline No. & & A & B & $\mathrm{C}$ & D & $\mathrm{E}$ & $\mathrm{F}$ & G \\
\hline \multicolumn{9}{|c|}{ Clinopyroxene Analyses } \\
\hline \multirow[t]{2}{*}{ Di } & (M) & 88 & 73 & 38 & 2.8 & 8.8 & 19 & 2.7 \\
\hline & $(\sigma)$ & 2.0 & 6.3 & 4.2 & 2.1 & 1.8 & 4.4 & 3.0 \\
\hline \multirow[t]{2}{*}{ Jo } & (M) & 2.1 & 1.2 & 2.2 & 2.6 & 8.2 & 27 & 52 \\
\hline & $(\sigma)$ & 0.46 & 0.41 & 0.88 & 0.06 & 1.9 & 4.5 & 10 \\
\hline \multirow[t]{3}{*}{$\mathrm{Hd}$} & (M) & 10 & 26 & 58 & 95 & 83 & 54 & 46 \\
\hline & $(\sigma)$ & 1.7 & 6.1 & 3.9 & 2.2 & 3.3 & 7.5 & 8.5 \\
\hline & \multicolumn{8}{|c|}{ Coexisting Fluid Compositions } \\
\hline \multirow[t]{3}{*}{$\mathrm{Mg}$} & (M) & 17 & 10 & 2.7 & 0.13 & 0.35 & 0.48 & 0.04 \\
\hline & $(\sigma)$ & 3.0 & 2.8 & 0.51 & 0.04 & 0.07 & 0.11 & 0.01 \\
\hline & (c.v.) & 17 & 27 & 19 & 30 & 19 & 23 & 13 \\
\hline \multirow[t]{3}{*}{$\mathrm{Mn}$} & (M) & 42 & 16 & 15 & 12 & 33 & 71 & 85 \\
\hline & $(\sigma)$ & 4.7 & 4.1 & 3.6 & 2.5 & 5.7 & 5.3 & 3.8 \\
\hline & (c.v.) & 11 & 25 & 23 & 21 & 17 & 7.4 & 4.5 \\
\hline \multirow[t]{3}{*}{$\mathrm{Fe}$} & (M) & 41 & 74 & 82 & 88 & 67 & 28 & 15 \\
\hline & $(\sigma)$ & 3.8 & 4.2 & 3.5 & 2.5 & 5.7 & 5.5 & 3.8 \\
\hline & (c.v.) & 9.2 & 5.8 & 4.8 & 2.8 & 8.6 & 19 & 27 \\
\hline
\end{tabular}

${ }^{*}(M)$ and $(\sigma)$ are the mean value and the standard deviation respectively expressed in mole percent of diopside (Di), johannsenite (Jo) and hedenbergite (Hd) components in the clinopyroxenes, and of the $\mathrm{Mg}, \mathrm{Mn}$ and Fe components in the computed coexisting hydrothermal fluids for the seven samples $(A-G)$ illustrated in Fig. 1. The percent coefficient of variation (c.v.) for the three components is also shown. ene departs from each end member component. That is, clinopyroxenes of samples $\mathrm{E}$ and $\mathrm{F}$ display larger compositional variations than those of sample D. This can be seen for the clinopyroxenes of sample $\mathrm{F}$ whose analyses display considerable scatter on the ternary diagram. According to the Fluctuation Model, this is expected because the proportions of the three components in the hydrothermal fluid and, in turn, in the growing clinopyroxene, increasingly fluctuate as the proportion of each component approaches equivalency (see Fig. 3).

Another feature of the clinopyroxene analytical data is that the compositions of individual sample analyses do not plot uniformly about the mean clinopyroxene composition on the ternary diagram. In general, clinopyroxenes of an individual sample have a tendency to be
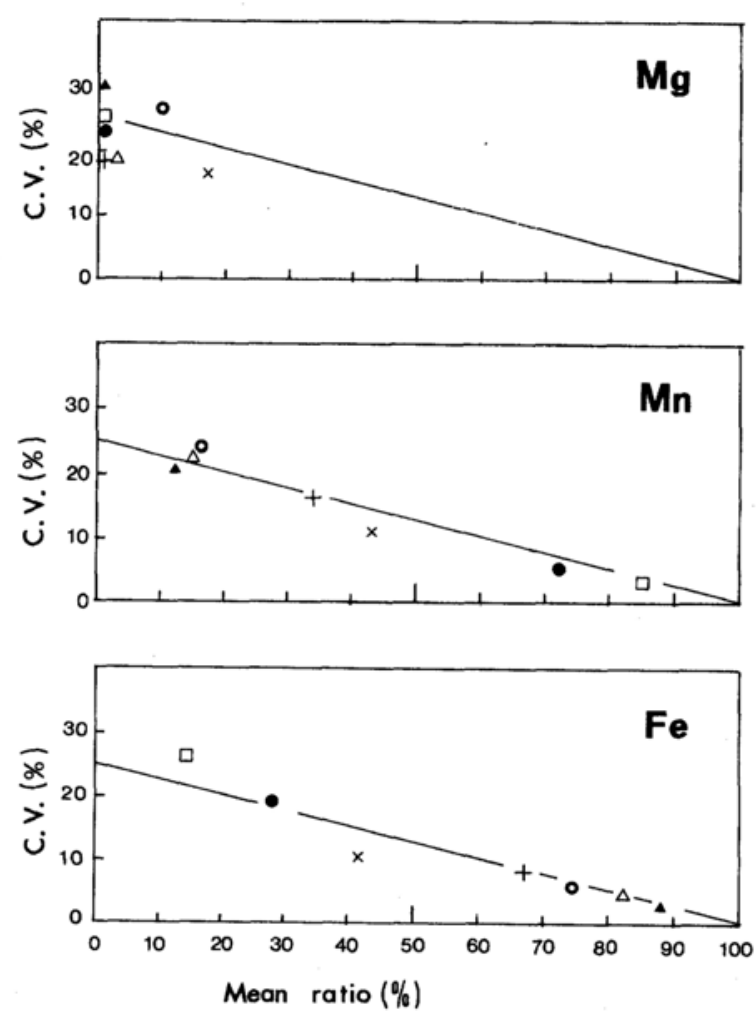

Fig. 6. Relation between the mean ratio and the coefficient of variation for $\mathrm{Mg}, \mathrm{Mn}$ and $\mathrm{Fe}$ components in the hydrothermal fluid expressed in mole percent. Symbols are the same as in Fig. 1. Note the linear relation between the two quantities. 
rich in the diopside component and poor in the johannsenite component. Most likely, this is due to the differences in the partition coefficients. That is, magnesium has a tendency to be highly concentrated and manganese less concentrated in the clinopyroxenes (see Fig. 5).

\section{SUMMARY}

The Fluctuation Model appears capable of explaining compositional variations which develop in clinopyroxenes during skarn formation. This model indicates that large heterogeneous variation of skarn clinopyroxene compositions (e.g., sample $\mathrm{F}$ in Fig. 1(A)) and systematic compositional variations of them (a positive $\mathrm{Fe}-\mathrm{Mn}$ correlation for sample $\mathrm{A}$ and a negative $\mathrm{Fe}-\mathrm{Mn}$ correlation for samples $\mathrm{D}$ and $\mathrm{E}$ ) can be reproduced simultaneously by the unsystematic fluctuation of fluid compositions. It should also be applicable to the study of heterogeneous mineralogical patterns in other multicomponent systems. However, several problems remain to be solved. For example, the temperature of skarn clinopyroxene formation is around 400$500^{\circ} \mathrm{C}$, which is slightly lower than the temperature $\left(600^{\circ} \mathrm{C}\right)$ at which partition coefficients have been experimentally determined. Nevertheless, minor modification of partition coefficients as a function of temperature will not invalidate the model.

Acknowledgments-The writer wishes to thank Prof.
H. Shimazaki and Dr. M. Shimizu who generously provided samples partly used in this study. Thanks are also due to Professors J. T. liyama and T. Fujii and Drs. Y. Kajiwara and C. W. Farrell for discussions and critical reading of the manuscript. Mr. N. Nishida has been of great help in providing EPMA technical assistance and Mr. Shirou Ozaki for drafting final versions of the Figures in this paper. This work was supported in part by the Grant-in-Aid for Special Research Project programme at the University of Tsukuba.

\section{REFERENCES}

Burton, J., Taylor, L. A., Chou, I. M. (1982) The $f_{\mathrm{O}_{2}}$ $-T$ and $f_{\mathrm{S}_{2}}-T$ stability relations of hedenbergite and of hedenbergite-johannsenite solid solutions. Econ. Geol. 77, 764-783.

Einaudi, M. T. and Burt, D. M. (1982) Introductionterminology, classification, and composition of skarn deposits. Econ. Geol. 77, 745-753.

Einaudi, M. T. (1977) Petrogenesis of the copper-bearing skarn at Mason Valley mine, Yerington district, Nevada. Econ. Geol. 72, 769-795.

Iiyama, J. T. (1979) Experimental study of the material transport in the earth's crust. Reports on the "The materials Science of The Earth's Interior"', Sunagawa, I. et al. eds., 50-53 ( Japanese).

Iiyama, J. T. (1982) Material transport in the Earth's crust and properties of mineral. J. Japan Assoc. Mineral. Petrol. Econ. Geol. (Special Issue 3), 291304 (Japanese).

Meinert, L. D. (1987) Skarn zonation and fluid evolution in the Groundhog mine, central mining district, New Mexico. Econ. Geol. 82, 523-545.

Nakano, T. (1982) Genesis of zoned skarn developed in diorite porphyry at the Kamaishi mine, Japan. $\mathrm{Ph}$. D thesis, Tsukuba Univ. $162 \mathrm{p}$. 